\title{
PROBLEMS AND KEY FACTORS OF CRM IMPLEMENTATION
}

CRM value chain identifies five key steps in the development and implementation of a CRM strategy: customer portfolio analysis, customer intimacy, network development, value proposition development, and manage customer life cycle. These five primary stages of the CRM value chain represent three main sequential phases of CRM strategy: analysis, resource development and implementation. This article deals with CRM value chain and diagnostics of the level of Slovak companies in the CRM area.

Keywords: CRM, CRM Value Chain, implementation, customer.

\section{Introduction}

In developed countries the change of business processes are distinguished in the orientation to a customer. Enterprises base their actions in the market not on "suspicions" or "experience", but on knowledge that is acquired by analysing customer's data. However knowledge-based activity of an enterprise is possible only when having processed the data on their basis motivated decisions to find, attract and keep customers are taken. This explains why at present it has particularly become fashionable to speak about customer relationship management (CRM) and CRM value chain.

CRM has a lot of definitions. CRM is everything what is related to satisfaction of customer's needs. Dick Lee states that CRM is perceived as "chain reaction", which is caused by new strategic initiatives of communication with a customer when high level of information technologies development and constant customer's need to get better quality of service are achieved [7].

Buttle understands customer relationship management as simply a bridge between marketing and information technologies. CRM decisions impact on marketing, operations, sales, customer service, human resources and information technologies [1].

CRM represents a business strategy designed to reduce costs and increase profitability by solidifying customer loyalty. CRM brings together information from all data sources within an organization to give one, view of each customer in real time. There are three key elements to a successful CRM initiative: people, process, and technology [5].

An interesting view on the term CRM has been brought by Payne. He understands customer relationship management as a strategic approach concerned with creating improved shareholder value through the development of appropriate relationships with key customers and customer segments. In his opinion CRM unites the potential of information technologies and relationship marketing strategies to deliver profitable, long-term relationships. CRM provides enhanced opportunities to use data and information both to understand customers and implement relationship marketing strategies better. This requires a cross-functional integration of people, operations, processes and marketing capabilities that is enabled through information technology and applications [8].

The rapid convergence of CRM and e-commerce has changed the face of enterprise customer relationship management and marketing. Today we can observe a boom of new services on the Internet. They have become very popular in a short time and they are used by millions of people all over the world [6].

\section{The CRM Value Chain}

The CRM value chain is a proven model which businesses can follow when developing and implementing their CRM strategies (Fig. 1). It has been five years in development and has been piloted in a number of business-to-business and business-to-consumer settings, with both large companies and small, medium enterprises: IT, software, telecoms, financial services, retail, media, manufacturing, and construction. The model is grounded on strong theoretical principles and the practical requirements of business [1].

The ultimate purpose of the CRM value chain process is to ensure that the company builds long-term mutually-beneficial relationships with its strategically - significant customers. Not all customers are strategically significant [1].

\footnotetext{
* Viliam Lendel

Department of Management Theories, Faculty of Management Science and Informatics, University of Zilina, Slovakia,

E-mail: viliam.lendel@fri.uniza.sk
} 


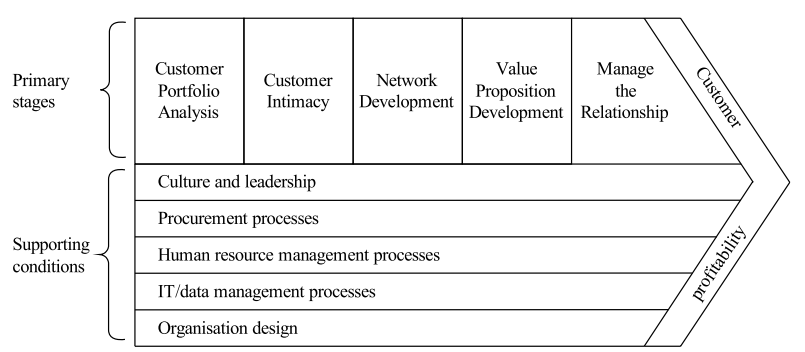

Fig. 1 The CRM value chain [1]

The CRM value chain has the five steps (Tab. 1). There are customer portfolio analysis (CPA), customer intimacy, network development, value proposition development and managing the relationship. At each stage of the value chain there are concepts, tools and processes to help create and implement successful strategy.

The CPA step analyses the customer base to identify customers to target with different value propositions [1]. CPA involves using customer and market data to decide which customers to serve. The companies are looking for groups of customers. They want to segment customer base. They want to determine which groups of customers are most profitable. Which customers spend the most on their goods and services? The result that the companies are looking for is their target customer base. They rate and segment their clients into groups that are most desirable to do business with because they meet their criteria for what a desirable customer are [2].

The second step involves the business in getting to know the selected customers as segments or individuals and building a customer data-base which is accessible to all those, whose decisions or activities impact upon customer attitude and behaviour [1]. This stage looks at the individual customer. Having found the segment(s) that the companies want to pursue, they want to get to know the people in that segment very well. They want to know them better than their competition knows them [2]. Customer intimacy involves getting to understand customers and their requirements.
Step three involves building a strong network of relationships with employees, suppliers, partners and investors who understand the requirements of the chosen customers [1].

Step four involves developing, with the network's compliance, propositions which create value jointly for the customer and company [2]. Network development and value proposition development are focused on building or acquiring resources to create and deliver value to customers [3].

The fifth and final stage is to manage the customer relationship. Managing the customer relationship is about implementing CRM by acquiring and retaining customers, and developing their value.

These steps are iterative and reflexive. They are iterative in the sense that the five-step process is repetitive and continuous. It is not a one-time process that leads to a strategy that is serviceable for ever. For example, in a dynamic environment in which competitors keep improving their value proposition it is important to review periodically which customers to serve, what to serve them and how to deliver the value [3]. Data are used across all 5 stages of the CRM Value Chain.

\section{Situation in Slovak enterprises}

From March 2007 to February 2009 I carried out the research specialized in diagnostics of the level of Slovak companies in the CRM area. For better understanding the value of the research, I addressed medium and large businesses. 230 top managers of Slovak medium (79\%) and large $(21 \%)$ businesses participated in the research.

Search subject has been companies acting in all branches of national industry on area of Žilina self-administrative region. Specifically it is about companies, relegated as medium and large companies on the base of employee count by Statistical Office of the Slovak Republic. Target group of the research are companies. For these companies it is essential to fulfill below written criteria of assortment to be sorted as target group:

Five stages of the CRM Value Chain [4]

Table 1

\begin{tabular}{|c|c|c|c|c|}
\hline $\begin{array}{c}\text { Customer Portfolio } \\
\text { Analysis }\end{array}$ & $\begin{array}{l}\text { Customer } \\
\text { Intimacy }\end{array}$ & $\begin{array}{c}\text { Network } \\
\text { Development }\end{array}$ & $\begin{array}{c}\text { Value Proposition } \\
\text { Development }\end{array}$ & $\begin{array}{c}\text { Manage } \\
\text { The Relationship }\end{array}$ \\
\hline $\begin{array}{l}\text { - Market segmentation } \\
\text { - Sales forecasting } \\
\text { - ABC } \\
\text { - Life-time value } \\
\text { - Customer analysis toolkit }\end{array}$ & $\begin{array}{l}\text { - Customer database } \\
\text { development } \\
\text { - Internal data } \\
\text { - Data enhancement } \\
\text { - Data warehousing } \\
\text { - Data mining } \\
\text { - Benchmarking } \\
\text { - Privacy } \\
\text { - Database technology and } \\
\text { software }\end{array}$ & $\begin{array}{l}\text { - Network management } \\
\text { - Internal buy-in } \\
\text { - External network } \\
\text { - Network position } \\
\text { - E-commerce } \\
\text { - EDI/Extranets/ Portals }\end{array}$ & $\begin{array}{l}\text { - Sources of customer value } \\
\text { - Customer experience } \\
\text { - Process reengineering } \\
\text { - People issues } \\
\text { - Technology enablement }\end{array}$ & $\begin{array}{l}\text { - Customer acquisition } \\
\text { - Customer retention } \\
\text { - Customer development } \\
\text { - Organisation design } \\
\text { - Metrics }\end{array}$ \\
\hline
\end{tabular}


- Acting on area of Žilina self-administrative region,

- Employees count higher than 50.

On the base of these criteria it can be said, that target group consists of medium and large companies, acting on area of Žilina self-administrative region. Object of the research (final respondents) are managers from middle or top management in these companies.

Representative technique has been chosen as sample selection method. To be specific, technique of base selection has been used. This technique uses full-range searching.

Sample size represents 210 of respondents (medium and large companies) by required $95 \%$ interval of reliability and maximal admissible fault $5 \%$ [9]. Actual count -230 respondents says that sample of asked companies may be considered as representative.

Data gathering was running by two main ways - by personal questioning and by electronic questionnaire. Telephone contact or email communication was made before personal questioning. Internet environment was also used for the data gathering. Electronic questionnaire was made through PHP and was placed on internet site of the faculty: http://fria.fri.uniza.sk/ lendel/dotaznik.php. By personal questioning it was gathered 121 questionnaires, which represents $53 \%$ of all questionnaires. Electronic questionnaire was filled by 109 managers from medium and large companies.

The purpose of the research was to find and analyse the current level of CRM area on the base of identifying main factors that affect the level of using CRM information system and process of implementation in the company. The current situation of CRM application based on results of the research is presented in Figure 2.

Almost one fourth of respondents (Fig. 2) did not deal with this problem. In the phase of study is 10 percent of respondents, 7 percent is in decision-making phase of CRM application importance for the company. 11 percent of respondents implements CRM in the company's practice. Almost half respondents (49 percent) said that CRM is in full operation in the company.

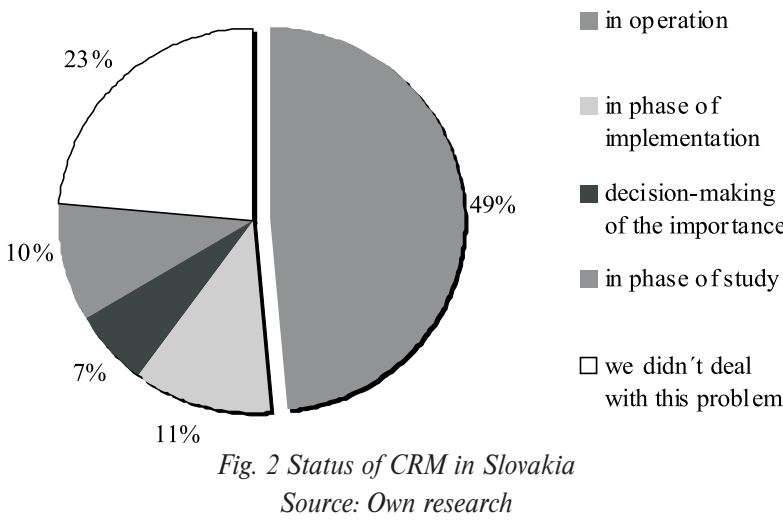

70 percent of respondents said that conception is the most important phase of CRM implementation process (Fig. 3). This phase informs about necessity of exactly defined criteria and conditions. 4 percent said that phase of selection, but on the other hand 17 percent said that phase of implementation is the most important. Main target of this phase is to successfully adapt the software and organizational structure. The phase of implementation finishes with testing and system realisation. 9 percent said about phase of realisation that it's the most important. For successful CRM information system implementation, it is necessary to have skilled employees. Assurance of regular communication is the most important in this phase.CRM implementation and CRM realization phase contains processes, which are essential for proofing and bringing the new CRM system to full operation in company. CRM is implemented into current company structure, where the software proofing is made and testing operation is running. After that the software is presented to company managers and eventual suggestions are being processed.

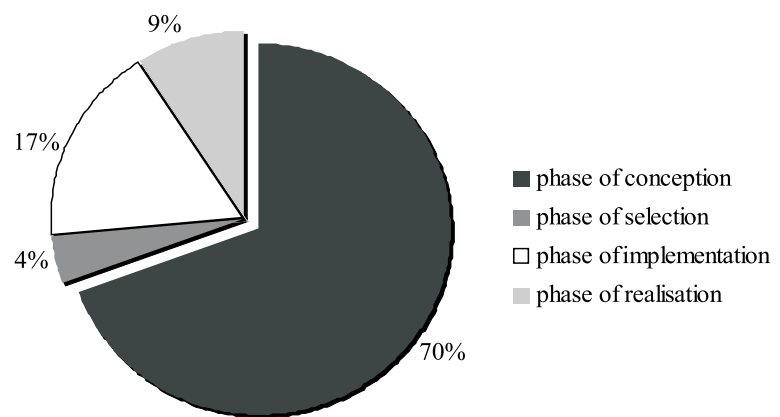

Fig. 3 Most important phase of process of CRM implementation in company's opinion

Source: Own research

The top managers identified the key problem areas of CRM implementation in the company. They selected the following problems:

- Change of customer demands.

- Loss of coordination (reason: very long process of implementation).

- Mismatched training.

- Permanent distrust of new technology.

- Mismatched definition of requisites before implementation.

- Insufficient consulting before installation.

- Insufficient details about processes and information flow.

- Low level of staff motivation.

- Insufficient trust between management and staff.

Top managers identified the following key problem areas of CRM implementation in the company:

- Low level of staff motivation (47.8\%).

- Insufficient details about processes and information flow (31.3\%).

- Mismatched definition of requisites before implementation (34.4\%).

- Permanent distrust of new technology (30.4\%).

As much as $54 \%$ asked companies consider application of CRM into company as continuous process. $12 \%$ of respondents 
quoted that CRM implementation lasted more than 12 months $14 \%$ of asked companies say that process lasted from 8 to 12 months, other $11 \%$ claim that duration was from 4 to 8 months and about $10 \%$ of respondents said the whole implementation process lasted less than 4 months.

Besides building the CRM in the company, $24 \%$ of asked companies used outsourcing services. $51 \%$ of respondents implemented CRM using own sources.

\section{Key elements influencing the CRM building in company}

Part of theoretical outputs of problem solution is also attempt to feature knowledge in the form of hexagonal stellar model (Fig. 4), which contains key elements influencing the CRM building in company. It consists of two triangles, each with elements representing main factors that influence CRM building in company:

- People.

- Processes.

- Technologies.

- Strategy.

- Organizational structure.

- Management.

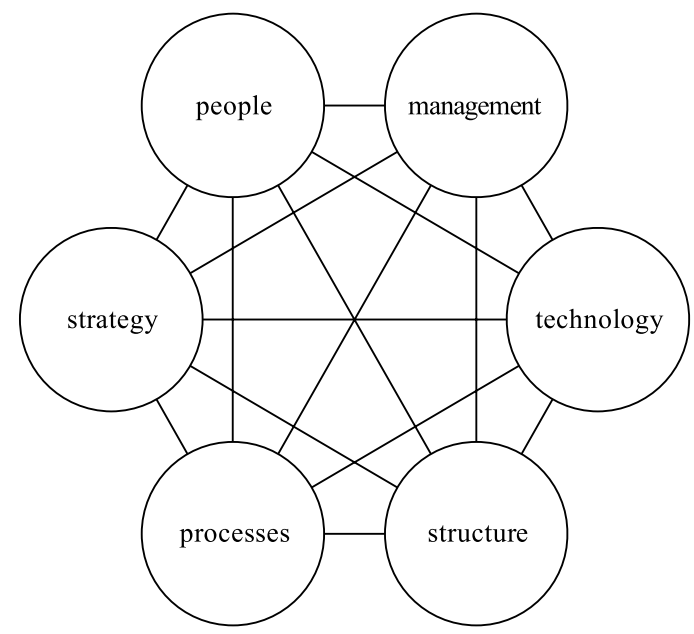

Fig. 4 Hexagonal stellar model Source: Own elaboration

Customer relationship management is in the sense of hexagonal stellar model understood as a compact system which includes vision, strategy, values of company culture and policy, company processes, their sources, goals and metrics with direct relation to customer.

The first triangle contains the key elements that form the main proportion (base) of the CRM. They are:

\author{
- People. \\ - Processes. \\ - Technologies.
}

Progress in the information technologies area provided the companies with methods of collection, saving, analyzing and sharing information about customers, which rapidly increased their ability to react on each customer's needs, to attract new and maintain current customers. Other important and indispensable element in the triangle are processes. All business processes in company should be oriented on customer. The most important element within the triangle are people. Success rate of building long-term and mutually profitable relations with customers will depend on performance and approach of people.

The second triangle contains elements that are important from the view of securing CRM function in company and are essential for building the CRM model. They create environment, in which the CRM can be built, and also resources and ways to achieve it. These elements are as follows:

- Strategy.

- Organizational structure.

- Management.

Support of top management and involvement of all employees is essential for successful CRM building in company. Creating the strategy is also important, same as in each key step in company run. Strategy with solid rules, but able to modify on the base of specific company conditions. These facts and changes have to reflect also in a new organizational structure of the company.

\section{Conclusion}

At present most organisations recognise evident benefit of CRM and almost every enterprise either uses certain CRM technologies, supporting its business, or evaluates specific benefit of the CRM technology and plans its future realisation.

For CRM to be truly effective, an organization must convince its staff that change is good and that CRM will benefit them. Then it must analyze its business processes to decide which need to be reengineered. Next is to decide what kind of customer information is relevant and how it will be used. Responsible team or top management must choose the right CRM solution. This process, depending upon the size of the company and the breadth of data, can take anywhere from a few weeks to a year or more.

Summarising viewpoints of various authors, it would be possible to highlight that in order to successfully implement CRM, it is necessary to balance and integrate technologies, processes and people. These elements are closely related to enterprise's strategy, processes of technologies, and processes of integration of overlapping functions as well as orientation to customers. 


\section{References}

[1] BUTTLE, F. The CRM Value Chain, Macquarie University, Sydney, April 2000, Available on Internet: www.wtcbrescia.it/upload/0FButtle_CRMvalchain.pdf

[2] STEVENSON, J. The CRM Value Chain. 2007, Available on Internet: http://it.toolbox.com/blogs/customer-centric/the-crm-valuechain-20548

[3] CRM Value Chain. Available on Internet, http://www.studymarketing.org/articles/Managing_CRM/CRM_Value_Chain.html

[4] Customer Relationship Management, Concepts and Tools. Chapter 2, The Customer Relationship Management Value Chain. Available on internet: www.sm.au.edu/uploadfiles/1181004054_Chapter_2_the_crm_value_chain.ppt

[5] What is CRM? Available on internet: http://www.destinationcrm.com/Articles/CRM-News/Daily-News/What-Is-CRM-46033.aspx

[6] KUBINA, M.: Nontraditional tools of marketing on the Internet: Journal of Information, Control and Management systems, Faculty of Management Science and Informatics, University of Zilina, 2008. Vol. 6, 2/2008. ISSN 1336-171

[7] LEE, D. Why climb the CRM mountain? The Customer Relationship Primer, 2nd ed., 2001, Available on Internet: http://sirnet.metamatrix.se/material/SIRNET_bakgrundsmaterial/CRM_0105.pdf

[8] PAYNE A.: Handbook of CRM: Achieving Excellence in Customer Management, Butterworth-Heinemann, 2005. ISBN 978-075066437-0, 2005.

[9] http://www.raosoft.com/samplesize.html 